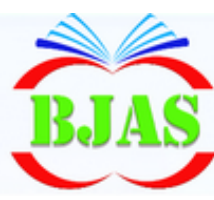

ISSN $1814-5868$
Available online at http://bajas.edu.iq

https://doi.org/10.37077/25200860.2021.34.sp1.7

College of Agriculture, University of Basrah

Basrah J. Agric. Sci., 34(Special Issue 1), 63-72, 2021

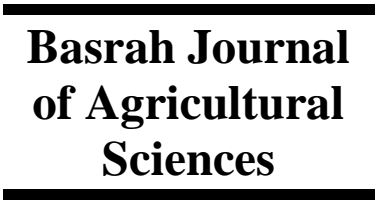

E-ISSN: 2520-0860

\title{
Evaluation of Fertilizer Electrical Conductivity (EC) and Temperature Distribution via Vertical Farming System under Plant Factory
}

\author{
Ahmad S. S. Sulaiman ${ }^{\text {* }}$, Mohammad A. Ahmad ${ }^{2}$, Seri A. Hassim², \& Muhamad S. A. \\ Azman $^{2}$ \\ ${ }^{1}$ Smart and Precision Agriculture Programme, Engineering Research Centre, MARDI \\ Headquarters Serdang, 43400 Selangor, Malaysia \\ ${ }^{2}$ Horticultural Research Centre, MARDI Headquarters Serdang, 43400 Selangor, Malaysia \\ *Corresponding Author E-mail: syafik@mardi.gov.my \\ Received 19 September 2019; Accepted 2 April 2021; Available online 20 August 2021
}

\begin{abstract}
A plant factory has been developed at Horticultural Research Centre, MARDI Serdang. The cultivation approach under the plant factory consists of nine units planting racks with each rack having seven tiers or levels that can cultivate up to 900 crops per rack. Each unit of planting racks has been installed with electrical conductivity (EC) and $\mathrm{pH}$ monitoring system. EC is a meaningful indicator of water quality, soil salinity and fertilizer concentration. In this study, the data for EC and temperature were taken for each level different locations (three points along the rack) to evaluate the fertilizer quality distribution. The objective of the study was to evaluate the effectiveness of EC and temperature distribution on the planting rack of vertical farming system under the plant factory. From the study, it was found that EC and temperature parameters were not significantly different at each level and the point location of the vertical farming system. EC and temperature parameters were significantly different with the time (week) and point location from week to week. The effect of the interaction between time (week) and level on EC and temperature parameters were not statistically different. Therefore, it can be concluded that the effect of EC and temperature distribution at different levels of the vertical farming system did not depend on the time.
\end{abstract}

Keywords: Plant factory, vertical farming system, fertilizer concentration distribution, Electrical Conductivity and temperature monitoring.

\section{Introduction}

A plant factory is a closed growing system/ structures which enable a farmer to achieve constant production of crops all year around. The facility utilizes artificial control of light, temperature, moisture, and carbon dioxide concentrations. Nowadays, the method is receiving importance and gaining the intention of the growers. The method can provide sufficient food supply throughout the year. In the system, the plant grows around the year by artificially adjusting and controlling the surrounding environmental conditions such as temperature, carbon dioxide $\left(\mathrm{CO}_{2}\right)$, humidity, light intensity, airflow, and nutrients supply within the confined facilities (Moon et al., 2014; Lee \& Yoe, 2015) . Besides, the system minimised environmental impact and maximised the crop yield with significant results as compared with traditional (openfield) cultivation system (Stanghellini, 2014). With a growing human population, there is a growing need for sustainable practices, 
especially within agriculture. As the population increases, so does the number of resources used to provide for it. Vertical farming technology has the potential to impact the world economically, environmentally, and socially. Recently, the application of vertical farming into cities has increased due to the consciousness of the public about food safety. The main idea behind vertical farms is to reduce the overall amount of resources used and to decrease agriculture's carbon footprint.

Plant physiology, growth, and development are closely associated with the environmental conditions and nutrient supply (Savvas et al., 2008; Signore et al., 2016). Evaluation of the optimum fertilizer/ nutrient application to crops is fundamental to improve crop production, especially for fast-growing leafy vegetables (Gorbe \& Calatayud, 2010; Haydon et al., 2015). Inadequate management of nutrient solution such as the use of a too high or a too low concentration of the nutrient solution, or an imbalanced ion composition could inhibit plant growth due to either toxicity or nutrient-induced deficiency (Benke \& Tomkins, 2017). The electrical conductivity (EC) is an index of salt concentration and an indicator of electrolyte concentration of the solution. EC of the nutrient solution is related to the number of ions available to crops in the root zone. The optimal EC is crop-specific and depends on environmental conditions. In general, higher EC hinders nutrient uptake by increasing the osmotic pressure of the nutrient solution, wastes nutrients, and the increases discharged of nutrients into the environment, resulting in environmental pollution (Kalantari et al., 2017). Lower EC may severely affect plant health and yield.

The National Policy on Industry 4.0 also known as Industry 4WRD is one of the initiatives by the government of Malaysia to enhance the implementation of precision agriculture in the industry (Ministry of International Trade and Industry, 2018). Precision agriculture has been popularized since the evolution of industrial revolution (IR) was introduced in the late 1960s.. Besides, the concept requires producers and farmers to communicate with technology rather than operating them. In this paper. The objective of this study is to evaluate the effectiveness of the vertical farming system that have been developed under the plant factory in order to control and monitor the irrigation for EC and temperature distribution. The objective can be related to the policy via using the precision technique for monitoring system.

\section{Materials \& Methods}

\section{Vertical farming system description and operation}

The planting racks (vertical farming system) was developed into a seven tiers/ levels of nutrient film technique (NFT) hydroponic container to cultivate crops. It consists of three main components which were fertilizer tank, planting rack and hydroponic container. The vertical farming system height is $7 \mathrm{~m}$, which each rack has a length of $2.5 \mathrm{~m}$, width $0.9 \mathrm{~m}$ and height of $0.12 \mathrm{~m}$ (Fig. 1). The most important component of this vertical farming system is the EC monitoring system in which a sensor has been installed inside the fertilizer tank and a monitor that will display the reading at the planting rack (fig. (2)). Each rack/ tier can accommodate up to 900 crops at one time and for seven tiers at the vertical farming system can cultivate up to 6300 crops.

\section{Lettuce Cultivation}

Lactuca Sativa of Red Coral and Butterhead were planted in a Nutrient Film Technique (NFT) hydroponics plot of $0.9 \mathrm{~m}$ wide, $0.01 \mathrm{~m}$ thick and $2.5 \mathrm{~m}$ long that vertically arranged 
under planting rack structure (Figs. 3 and 4). The water level inside the growing container was $0.08 \mathrm{~m}$ which can reach by the crop roots. The crop spacing was $0.01 \mathrm{~m}$, and for $2.5 \mathrm{~m}$ long of growing container it can accommodate near 900 crops. Lactuca Sativa was transplanted under the crop protection structure after three weeks of seeding in nursery. The crops were transplanted and grow inside the plant factory for three weeks before harvested. The lettuce of Red Coral and Butterhead were used in this study due to its high price and can be easily grown using the hydroponic system.

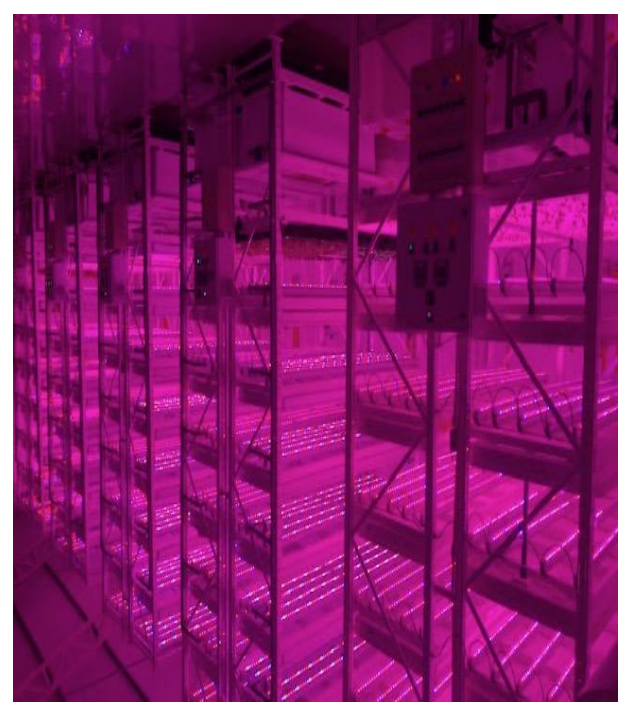

Fig. (1): Vertical farming system.

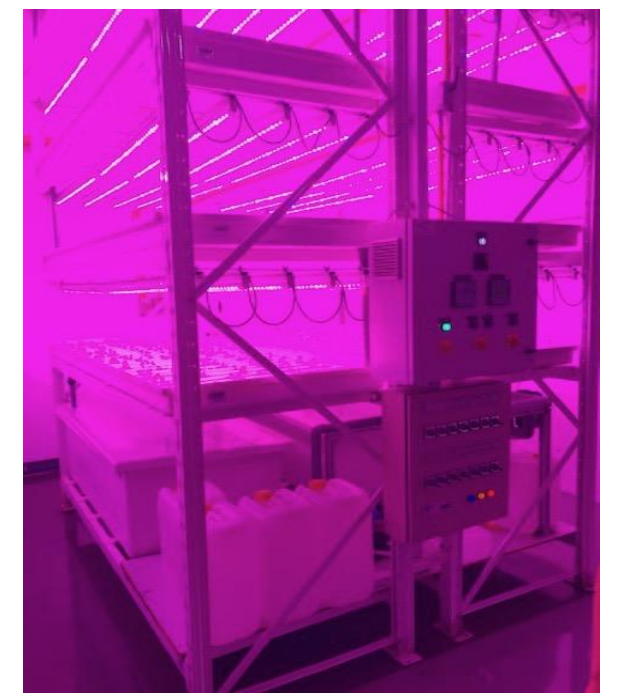

Fig. (2): Fertilizer monitoring system.

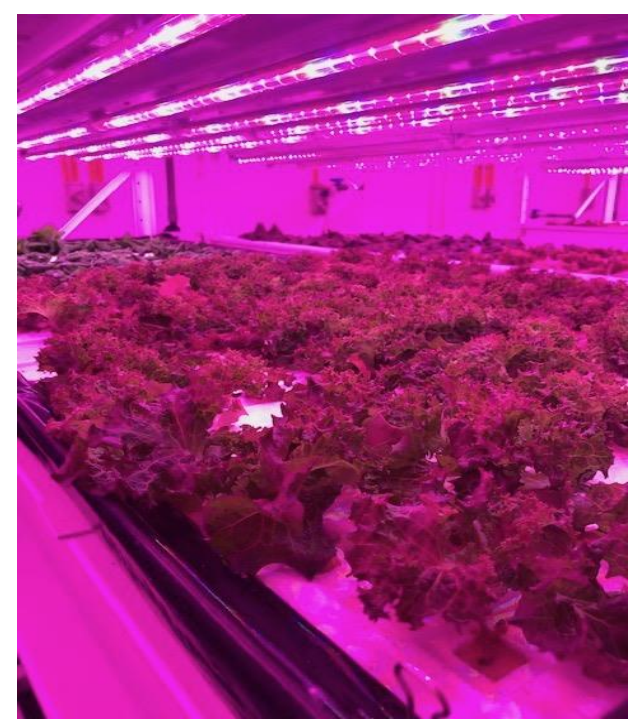

Fig. (3): Red Coral lettuce.

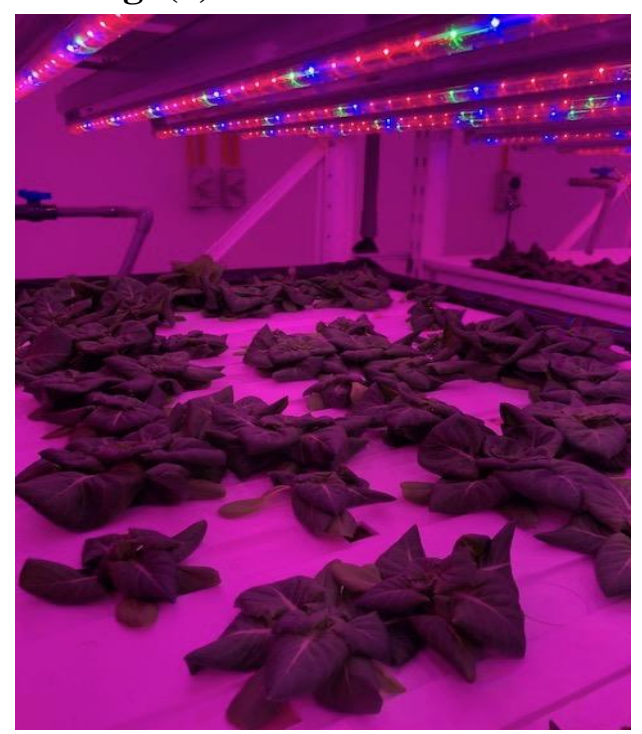

Fig. (4): Butterhead lettuce

\section{Data collection}

Data collection have been conducted on 7 tiers of planting rack under plant factory in MARDI Serdang, Selangor, Malaysia. Handheld EC and temperature sensors have been used to record EC and temperature reading at three point locations at each hydroponic container (inlet, middle and outlet) on the planting rack. Data were recorded at 60 minutes' interval time for 8 hours per day from 8.00 a.m. to 5.00 p.m. for 6 weeks. The data were recorded after the crop was transplanted from the nursery to the plant factory. 


\section{Fertilizer flow rate calculation}

The fertilizer flow rate can be determined if the water pump power capacity of the water and the force (pressure) required to produce that flow are known. The following formula was used to calculate fertilizer flow rate as shown in Equation 1 (Pritchard, 2011):

$\mathrm{Q}=\frac{\text { water horsepower } \times 3960}{T D H \times S G}$

water horsepower is the minimum power required to run the water pump, TDH is total dynamic head equals to vertical distance liquid travels (in feet) and friction loss from the pipe, $\mathrm{Q}$ is the flow rate of liquid in gallons per minute, and SG is the specific gravity of the liquid which in this case is the SG of fertilizer use for fertilizing the crops. The specific gravity $(s g$ ) of the liquid fertilizer should be provided by the fertilizer provider.

\section{Data Analysis}

The data obtained were subjected to descriptive statistics, analysis of variance (ANOVA) and correlation analysis. All the statistical analysis was carried out using SAS statistical software (Version 9.4, SAS Institute, USA).

\section{Results \& Discussion}

EC and temperature of fertilizer distribution on the vertical farming system

Table (1) shows the EC and temperature at three point locations at different levels of the vertical farming system. The EC fluctuated along the levels for left, middle, and right locations of the hydroponic tank at each level of the vertical farming system, ranging from $2.16-2.20 \mu \mathrm{S}$, respectively. The standard deviation was quite low which was between 0.03 to $0.09 \mu \mathrm{S}$. The temperature increased significantly along the levels for left, middle, and right locations ranging from 25.17 - 25.65 ${ }^{\circ} \mathrm{C}$, respectively. For temperature, low standard deviation was also achieved which was between 0.81 to $1.00{ }^{\circ} \mathrm{C}$. In this case, both parameters were not significantly different with the level and point location.

Table (2) shows the EC and temperature in three point locations for each level of the vertical farming system at different weeks. The EC increased significantly along the weeks for left, middle, and right locations ranging from $2.12-2.30 \mu \mathrm{S}$, respectively. The standard deviation was quite low which was between 0.01 to $0.07 \mu \mathrm{S}$. The temperature fluctuated along the weeks for left, middle, and right locations ranging from $24.16-26.90{ }^{\circ} \mathrm{C}$, respectively. For temperature, low standard deviation was also achieved which was between 0.13 to $0.47{ }^{\circ} \mathrm{C}$. In this case, both parameters were significantly different with the week and point location.

Normally, the environmental factors including temperature, humidity, light, and $\mathrm{CO}_{2}$ concentration are essential in the crop growth and quality via plant factory system. Proper temperature is needed depending on the type of crops in order to evaluate the germination and growth of the crops (Ryu et al., 2014).

Maneejantra et al. (2016) studied the cultivation of spinach in a plant factory which was highly influenced by the nutrient content, environmental conditions, and hydroponic system. In a similar study, Engelen-Eigles et al. (2006) developed a potential commercial system via plant factory to determine the effect of temperature and light intensity on the growth of watercress. It can be noted that high temperature resulted in a decrease in photosynthesis rates as well as reduced wateruse efficiency for the crop growth (Sakamoto \& Suzuki, 2015). 
Sulaiman et al. / Basrah J. Agric. Sci., 34(Special Issue 1): 63-72, 2021

Table (1): EC and temperature in three point locations at different levels.

\begin{tabular}{lllll}
\hline \multirow{2}{*}{ Level } & \multirow{2}{*}{ Parameter } & Point location & & \\
\cline { 3 - 5 } & & Left & Middle & Right \\
\hline \multirow{2}{*}{ Control } & EC & $2.16 \pm 0.06^{\mathrm{a}}$ & $2.16 \pm 0.06^{\mathrm{a}}$ & $2.16 \pm 0.06^{\mathrm{a}}$ \\
& Temperature & $25.27 \pm 1.00^{\mathrm{a}}$ & $25.27 \pm 1.00^{\mathrm{a}}$ & $25.27 \pm 1.00^{\mathrm{a}}$ \\
\hline \multirow{2}{*}{1} & EC & $2.20 \pm 0.05^{\mathrm{a}}$ & $2.18 \pm 0.09^{\mathrm{a}}$ & $2.19 \pm 0.05^{\mathrm{a}}$ \\
& Temperature & $25.17 \pm 0.97^{\mathrm{a}}$ & $25.23 \pm 0.98^{\mathrm{a}}$ & $25.18 \pm 1.00^{\mathrm{a}}$ \\
\hline \multirow{2}{*}{2} & EC & $2.20 \pm 0.06^{\mathrm{a}}$ & $2.20 \pm 0.07^{\mathrm{a}}$ & $2.20 \pm 0.06^{\mathrm{a}}$ \\
& Temperature & $25.23 \pm 0.97^{\mathrm{a}}$ & $25.23 \pm 0.98^{\mathrm{a}}$ & $25.25 \pm 0.97^{\mathrm{a}}$ \\
\hline \multirow{2}{*}{3} & EC & $2.19 \pm 0.07^{\mathrm{a}}$ & $2.20 \pm 0.07^{\mathrm{a}}$ & $2.20 \pm 0.09^{\mathrm{a}}$ \\
& Temperature & $25.17 \pm 0.96^{\mathrm{a}}$ & $25.22 \pm 0.93^{\mathrm{a}}$ & $25.22 \pm 0.90^{\mathrm{a}}$ \\
\hline \multirow{2}{*}{4} & EC & $2.16 \pm 0.03^{\mathrm{a}}$ & $2.18 \pm 0.03^{\mathrm{a}}$ & $2.16 \pm 0.05^{\mathrm{a}}$ \\
& Temperature & $25.17 \pm 0.96^{\mathrm{a}}$ & $25.18 \pm 0.94^{\mathrm{a}}$ & $25.18 \pm 0.94^{\mathrm{a}}$ \\
\hline \multirow{2}{*}{5} & EC & $2.19 \pm 0.06^{\mathrm{a}}$ & $2.19 \pm 0.06^{\mathrm{a}}$ & $2.18 \pm 0.07^{\mathrm{a}}$ \\
& Temperature & $25.28 \pm 0.96^{\mathrm{a}}$ & $25.30 \pm 1.01^{\mathrm{a}}$ & $25.23 \pm 0.99^{\mathrm{a}}$ \\
\hline \multirow{2}{*}{6} & EC & $2.17 \pm 0.07^{\mathrm{a}}$ & $2.17 \pm 0.09^{\mathrm{a}}$ & $2.19 \pm 0.06^{\mathrm{a}}$ \\
& Temperature & $25.65 \pm 0.85^{\mathrm{a}}$ & $25.50 \pm 0.83^{\mathrm{a}}$ & $25.35 \pm 0.90^{\mathrm{a}}$ \\
\hline
\end{tabular}

* Different letters within the same column indicate statistical difference by the Tukey's test, $\mathrm{P}<0.05$ for seven levels.

Table (2): EC and temperature in three point locations at different weeks.

\begin{tabular}{lllll}
\hline \multirow{2}{*}{ Week } & \multirow{2}{*}{ Parameter } & Point location & \\
\cline { 3 - 5 } & & Left & Middle & Right \\
\hline \multirow{2}{*}{1} & EC & $2.13 \pm 0.04^{\mathrm{b}}$ & $2.12 \pm 0.03^{\mathrm{c}}$ & $2.13 \pm 0.04^{\mathrm{b}}$ \\
& Temperature & $25.04 \pm 0.47^{\mathrm{cd}}$ & $24.99 \pm 0.31^{\mathrm{c}}$ & $25.04 \pm 0.47^{\mathrm{c}}$ \\
\hline \multirow{2}{*}{2} & EC & $2.17 \pm 0.01^{\mathrm{b}}$ & $2.15 \pm 0.04^{\mathrm{bc}}$ & $2.17 \pm 0.01^{\mathrm{b}}$ \\
& Temperature & $25.40 \pm 0.19^{\mathrm{bc}}$ & $25.46 \pm 0.24^{\mathrm{b}}$ & $25.40 \pm 0.19^{\mathrm{b}}$ \\
\hline \multirow{2}{*}{3} & EC & $2.18 \pm 0.04^{\mathrm{b}}$ & $2.19 \pm 0.05^{\mathrm{b}}$ & $2.18 \pm 0.04^{\mathrm{b}}$ \\
& Temperature & $24.16 \pm 0.18^{\mathrm{e}}$ & $24.19 \pm 0.16^{\mathrm{d}}$ & $24.16 \pm 0.18^{\mathrm{e}}$ \\
\hline \multirow{2}{*}{4} & EC & $2.17 \pm 0.01^{\mathrm{b}}$ & $2.17 \pm 0.01^{\mathrm{bc}}$ & $2.17 \pm 0.01^{\mathrm{b}}$ \\
& Temperature & $25.50 \pm 0.22^{\mathrm{b}}$ & $25.50 \pm 0.17^{\mathrm{b}}$ & $25.50 \pm 0.15^{\mathrm{b}}$ \\
\hline \multirow{2}{*}{5} & EC & $2.17 \pm 0.03^{\mathrm{b}}$ & $2.17 \pm 0.03^{\mathrm{bc}}$ & $2.17 \pm 0.03^{\mathrm{b}}$ \\
& Temperature & $24.70 \pm 0.18^{\mathrm{d}}$ & $24.69 \pm 0.16^{\mathrm{c}}$ & $24.70 \pm 0.18^{\mathrm{d}}$ \\
\hline \multirow{2}{*}{6} & EC & $2.28 \pm 0.07^{\mathrm{a}}$ & $2.30 \pm 0.04^{\mathrm{a}}$ & $2.28 \pm 0.07^{\mathrm{a}}$ \\
& Temperature & $26.90 \pm 0.13^{\mathrm{a}}$ & $26.90 \pm 0.13^{\mathrm{a}}$ & $26.90 \pm 0.13^{\mathrm{a}}$ \\
\hline
\end{tabular}

* Different letters within the same column indicate statistical difference by the Tukey's test, $\mathrm{P}<0.05$ for six weeks. 
Chen et al. (2016) studied the growth of Boston lettuce and coral lettuce for 14 days for germination with the nutrient solution circulating between the planting beds and storage tank with a pump in order to maintain the uniformity of the nutrient intake. An efficient plant factory governed by factors that affected the crop growth which was light intensity, $\mathrm{EC}, \mathrm{pH}$, temperature, humidity, $\mathrm{CO}_{2}$, etc. (Amado et al., 2016; Shamshiri et al., 2018). To evaluate the potential of the vertical farming system under plant factory, Tamura $e t$ al. (2018) investigated the phytochemical accumulation and yield of leaf lettuce in conjunction with various growth factors including temperature, EC, and light intensity. In other research, Hasegawa et al. (2014) reported the change in $\mathrm{CO}_{2}$ and temperature in relation to the growth of the plant samples. It was revealed that plants cultivated at low temperature showed high photosynthesis rates compared to the plants cultivated at high temperature. Hence, it can be noted that temperature was vital in the plant growth and yield under plant factory system.

Pearson correlation between EC and temperature of fertilizer distribution

Table (3) shows the ANOVA of EC and temperature parameters: left point temperature (T1), middle point temperature (T2), right point temperature (T3), left point EC (EC1), middle point $\mathrm{EC}(\mathrm{EC} 2)$, and right point $\mathrm{EC}$ (EC3). The ANOVA analysis results showed that the EC and temperature parameters were significantly influenced by the week at $\mathrm{P}<0.05$.

Table (3): Analysis of variance (ANOVA) of EC and temperature parameters.

\begin{tabular}{llll}
\hline Factors & Parameters & Mean square & P<0.05 \\
\hline Week & EC1 & 0.020 & $<.0001^{*}$ \\
& T1 & 6.930 & $<.0001^{*}$ \\
EC2 & 0.030 & $<.0001^{*}$ \\
& T2 & 6.938 & $<.0001^{*}$ \\
& EC3 & 0.021 & $<.0001^{*}$ \\
& T3 & 6.744 & $<.0001^{*}$ \\
\hline Level & EC1 & 0.002 & 0.8938 \\
& T1 & 0.145 & 0.9917 \\
& EC2 & 0.001 & 0.9683 \\
& T2 & 0.063 & 0.9994 \\
EC3 & 0.002 & 0.8881 \\
& T3 & 0.061 & 0.9994 \\
\hline ECevel & E1 & 0.001 & 0.8924 \\
& T1 & 0.050 & 0.8952 \\
& EC2 & 0.001 & 0.9994 \\
& T2 & 0.039 & 0.9935 \\
EC3 & 0.002 & 0.9843 \\
& T3 & 0.048 & 0.8999
\end{tabular}

Abbreviation of variables were T1: left point temperature, T2: middle point temperature, T3: right point temperature, EC1: left point EC, EC2: middle point EC, and EC3: right point EC.

* The means are significant at $\mathrm{P}<0.05$. 
The highest mean square was recorded for T2 with the values of 6.938. Meanwhile, the EC and temperature parameters were not significantly influenced by the levels with the highest mean square of 0.145 for T1. It was observed that the effect of the interaction between week and level on EC and temperature parameters were not statistically different (T1, T2, T3, EC1, EC2, and EC3). In other words, the effect of different levels does not depend on the week.

In a study conducted by Baek et al. (2016), temperature and air flow stagnation were important for the plant cultivation in order to determine the crop quality and growth in a vertical type plant factory. Tamura et al. (2018) suggested that the growth and quality of vegetables cultivated in the plant factory were influenced by the temperature, humidity, light source, and fertilizer. Lee et al. (2019) reported the growth of crisphead lettuce by comparing the type of cultivar, temperature and light intensity. It was revealed that the growth of crisphead lettuce was significantly influenced by temperature in low light intensity condition for all type of cultivars.
Similarly, Lee et al. (2013) investigated the productivity and quality of lettuce under artificial plant factory, indicating that low temperature conditions were applied to avoid tipburn due to reduction of photosynthetic rates.

The Pearson correlation coefficients between EC and temperature from different point locations are presented in table (4). The results demonstrated that the strong correlation was achieved between EC and temperature parameters to determine the growth of lettuce. All parameters were significantly different with the growth of lettuce at $p<0.05$. Based on the result, the EC3 was positively correlated to the EC1 $(r=0.942)$. Among the EC and temperature parameters values, the highest correlation was recorded between $\mathrm{T} 2$ and $\mathrm{T} 3$ (r $=0.995)$. These observations showed the discrepancy in both EC and temperature parameters that could be explained by the importance of these parameters in the growth of lettuce. In this case, the EC and temperature parameters were feasible in determining the quality and growth of lettuce in the plant factory system.

\section{Table (4): Pearson correlation coefficients between EC and temperature from different point}

\section{locations.}

\begin{tabular}{llllll}
\hline & EC1 & T1 & EC2 & T2 & EC3 \\
\hline T1 & $0.517^{*}$ & & & & \\
\hline EC2 & $0.883^{*}$ & $0.521^{*}$ & & & \\
\hline T2 & $0.535^{*}$ & $0.991^{*}$ & $0.546^{*}$ & & \\
\hline EC3 & $\mathbf{0 . 9 4 2 *}$ & $0.454^{*}$ & $0.883^{*}$ & $0.475^{*}$ & \\
\hline T3 & $0.511^{*}$ & $0.987^{*}$ & $0.517^{*}$ & $\mathbf{0 . 9 9 5 *}$ & $0.448^{*}$ \\
\hline
\end{tabular}

Abbreviation of variables were T1: left point temperature, T2: middle point temperature, T3: right point temperature, EC1: left point EC, EC2: middle point EC, and EC3: right point EC.

* The means are significant at $\mathrm{P}<0.05$. 


\section{Fertilizer flow rate calculation}

Using the Hydroponic Nutrient Film Technique (NFT) we don't need to fill full water into growing container, just need a constant flow of fertilizer to the crops. The water depth is shallow, only a few mm (1/4 inch) so we don't need a large volume of water to be pumped through it. The pump just needs to be able to keep up with how fast the water is flowing out of the tubes. Typically, NFT system are constructed using long tubes that are angled so the water flows downhill as it flows through the tube.

*A pipe friction loss charts 1" PVC pipe cause a loss of $6.3 \mathrm{ft}$ of head every $100 \mathrm{ft}$, all 1 " PVC pipe in the vertical farming system have $1.2 \mathrm{~m}$ long in total equal to $4 \mathrm{ft}$. so, $(4 \mathrm{ft}$ x $6.3 \mathrm{ft}$ ) $/ 100 \mathrm{ft}=0.252 \mathrm{ft}$ head. Looks up the friction loss from each fitting in the pipe. For 1" PVC pipe, one $90^{\circ}$ elbow connector and three treaded fitting contribute to a total loss of $15 \mathrm{ft}$. adding this all together, the total friction loss is $0.252+15=15.252 \mathrm{ft}$ (friction)

Vertical distance of NFT hydroponic growing container is 2.5 meter, equal to $8.2 \mathrm{ft}$

$$
\begin{aligned}
\mathrm{TDH} & =15.252+8.2 \\
& =23.45 \mathrm{ft}
\end{aligned}
$$

And from fertilizer provider, SG for fertilizer is 1 , so

$\mathrm{Q}=\frac{\text { water horsepower } x 3960}{T D H \times S G}$

$$
\mathrm{Q}=\underline{0.5 \mathrm{Hp} \times 3960}=84.43 \mathrm{1} / \mathrm{min}
$$

\section{$23.45 \mathrm{ft} \times 1$}

The flow rate of fertilizer distribute to the 7 tiers of vertical farming is calculated at 84.43 $1 / \mathrm{min}$.

\section{Conclusion}

Based on the findings, the EC and temperature parameters were not significantly different with the level and point location. EC and temperature parameters were significantly different with the week and point location. The EC fluctuated along the levels ranging from 2.16-2.20 $\mu \mathrm{S}$, respectively. Meanwhile, the temperature increased significantly along the levels ranging from 25.17-25.65 ${ }^{\circ} \mathrm{C}$, respectively. The EC increased significantly along the weeks ranging from 2.12-2.30 $\mu \mathrm{S}$, respectively. Meanwhile, the temperature fluctuated along the weeks ranging from 24.16-26.90 ${ }^{\circ} \mathrm{C}$, respectively. The effect of the interaction between week and level on EC and temperature parameters were not statistically different. Therefore, the effect of different levels does not depend on the week. Thus, this technique provides a range of information which could be required to provide a greater understanding regarding the evaluation of fertilizer EC and temperature distribution via a vertical farming system.

\section{Acknowledgements}

The researchers would like to thank the staffs of Engineering and Horticultural Research Centre MARDI for their assistance. This research was supported by RMK11 Development project under the Ministry of Agriculture and Agro-Based Industry (MOA).

\section{Conflicts of Interest}

The authors declare no conflict of interest, and also the funders had no role in the design of the study; in the collection, analyses, or interpretation of data; in the writing of the manuscript, or in the decision to publish the results.

\section{References}

Amado, T. M., Valenzuela, I. C., \& Orillo, J. W. F. (2016). Horticulture of lettuce (Lactuva sativa L.) using red and blue LED with pulse lighting 
treatment and temperature control in snap hydroponics setup. Jurnal Teknologi, 78, 67-71. https://doi.org/10.11113/jt.v78.8804

Baek, M. S., Kwon, S. Y., \& Lim, J. H. (2016). Improvement of the crop growth rate in plant factory by promoting air flow inside the cultivation. International Journal of Smart Home, 10, 63-74. https://doi.org/10.14257/ijsh.2016.10.2.07

Benke, K., \& Tomkins, B. (2017). Future foodproduction systems: Vertical farming and controlled-environment agriculture. Sustainability: Science, Practice, and Policy, 13, 13-26. https://www.tandfonline.com/doi/full/10.1080/1548 7733.2017.1394054

Chen, W. T., Yeh, Y. H. F., Liu, T. Y., \& Lin, T. Te. (2016). An automated and continuous plant weight measurement system for plant factory. Frontiers in Plant Science, $\quad 7, \quad 1-9$. https://doi.org/10.3389/fpls.2016.00392

Engelen-Eigles, G., Holden, G., Cohen, J. D., \& Gardner, G. (2006). The effect of temperature, photoperiod, and light quality on gluconasturtiin concentration in watercress (Nasturtium officinale R. Br.). Journal of Agricultural and Food Chemistry, 54, 328-334. https://doi.org/10.1021/jf051857o

Gorbe, E., \& Calatayud, Á. (2010). Optimization of Nutrition in Soilless Systems: A Review. Advances in Botanical Research, 53, 193-45. https://doi.org/10.1016/S0065-2296(10)53006-4

Hasegawa, Y., Yamanaka, G., Ando, K., \& Uchida, H.(2014). Ambient temperature effects on evaluation of plant physiological activity using plant bioelectric potential. Sensors and Materials, 26, 461-470. https://doi.org/10.18494/SAM.2014.1008

Haydon, M. J., Román, Á., \& Arshad, W. (2015). Nutrient homeostasis within the plant circadian network. Frontiers in Plant Science, 6, 1-6. https://doi.org/10.3389/fpls.2015.00299

Kalantari, F., Tahir, O. M., Lahijani, A. M., \& Kalantari, S. (2017). A review of vertical farming technology: A guide for implementation of building integrated agriculture in cities. Advanced Engineering Forum, 24 , 76-91.

DOI: $10.4028 /$ www.scientific.net/AEF.24.76

Lee, J. G., Choi, C. S., Jang, Y. A., Jang, S. W., Lee, S. G., \& Um, Y. C. (2013). Effects of air temperature and air flow rate control on the tipburn occurrence of leaf lettuce in a closed-type plant factory system. Horticulture Environment and Biotechnology, 54, 303-310. https://doi.org/10.1007/s13580-013-0031$\underline{0}$

Lee, M., \& Yoe, H. (2015). Analysis of environmental stress factors using an artificial growth system and plant fitness optimization. Research International, 1-6. https://doi.org/10.1155/2015/292543

Lee, R. J., Bhandari, S. R., Lee, G., \& Lee, J. G. (2019). Optimization of temperature and light, and cultivar selection for the production of high-quality head lettuce in a closed-type plant factory. Horticulture Environment and Biotechnology, 60, 207-216. https://agris.fao.org/agrissearch/search.do?recordID=US201900259924

Maneejantra, N., Tsukagoshi, S., \& Lu, N. (2016). A Quantitative Analysis of Nutrient Requirements for Hydroponic Spinach (Spinacia oleracea L.) Production Under Artificial Light in a Plant Factory. Journal of Fertilizers \& Pesticides, 7, 2-5. https://doi.org/10.4172/2471-2728.1000170

Ministry of International Trade \& Industry (2018) Industry4WRD: National Policy on Industry 4.0. Malaysia: Ministry of International Trade and Industry.

https://www.malaysia.gov.my/portal/content/30610

Moon, S. M., Kwon, S. Y., \& Lim, J. H. (2014). Minimization of temperature ranges between the top and bottom of an air flow controlling device through hybrid control in a plant factory. Scientific World Journal, 2014, 801590, 7pp, 2014. https://doi.org/10.1155/2014/801590

Pritchard, P. (2011). Fox and McDonald's introduction to fluid mechanics, 8th ed. New York: John Wiley. 875pp.http://ftp.demec.ufpr.br/disciplinas/TM240/ Marchi/Bibliografia/Pritchard-FoxMcDonalds_2011_8ed_Fluid-Mechanics.pdf

Ryu, D. K., Kang, S. W., Ngo, V. D., Chung, S. O., Choi, J. M., Park, S. U., \& Kim, S. J.(2014). Control of temperature, humidity, and $\mathrm{CO} 2$ concentration in small- sized experimental plant factory. Acta Horticulturae, $\quad 1037, \quad 477-484$. https://doi.org/10.17660/ActaHortic.2014.1037.59

Sakamoto, M., \& Suzuki, T. (2015). Elevated root-zone temperature modulates growth and quality of hydroponically grown carrots. Agricultural Sciences, $\quad 6, \quad 749-757$. https://doi.org/10.4236/as.2015.68072 
Sulaiman et al. / Basrah J. Agric. Sci., 34(Special Issue 1): 63-72, 2021

Savvas, D., Ntatsi, G., \& Passam, H. C. (2008). Plant Nutrition and Physiological Disorders in Greenhouse Grown Tomato, Pepper and Eggplant. The European Journal of Plant Science and Biotechnology, 2, 45-61. http://www.globalsciencebooks.info/Online/GSBO nline/images/0812/EJPSB_2(SI1)/EJPSB_2(SI1)45 -61o.pdf

Shamshiri, R. R., Kalantari, F., Ting, K. C., Thorp, K. R., Hameed, I. A., Weltzien, C., Ahmad, D., \& Shad, Z. (2018). Advances in greenhouse automation and controlled environment agriculture: A transition to plant factories and urban agriculture. International Journal of Agricultural and Biological Engineering, 11, 1-22. DOI: $\underline{10.25165 / \text { j.ijabe.20181101.3210 }}$

Signore, A., Serio, F., \& Santamaria, P. (2016). A targeted management of the nutrient solution in a soilless tomato crop according to plant needs. Frontiers in Plant Science, 7, 1-15. https://doi.org/10.3389/fpls.2016.00391

Stanghellini, C. (2014). Horticultural production in greenhouses: Efficient use of water. Acta Horticulturae, 1034, 25-32. https://doi.org/10.17660/ActaHortic.2014.1034.1

Tamura, Y., Mori, T., Nakabayashi, R., Kobayashi, M., Saito, K., Okazaki, S., Wang, N., \& Kusano, M. (2018). Metabolomic evaluation of the quality of leaf lettuce grown in practical plant factory to capture metabolite signature. Frontiers in Plant Science, 9, $1-11$. https://doi.org/10.3389/fpls.2018.00665. eCollectio n 2018 